Original Research Paper

\title{
Detection and Solutions for Non-Technical Losses in Cameroon Electricity Network
}

\author{
${ }^{1}$ Lekini Nkodo Claude Bernard, ${ }^{1}$ Ndzana Benoît, ${ }^{1}$ Oumarou Hamandjoda and ${ }^{2}$ Fippo Fitime Louis \\ ${ }^{I}$ National Advanced School of Engineering, University of Yaounde I, Cameroon \\ ${ }^{2}$ Computer Science Laboratory, University of Paris 13, UMR CNRS 7030, France
}

\author{
Article history \\ Received: 30-11-2017 \\ Revised: 01-01-2018 \\ Accepted: 25-01-2018 \\ Corresponding Author: \\ Lekini Nkodo Claude Bernard \\ National Advanced School of \\ Engineering, University of \\ Yaounde I, Cameroon \\ Email: grhuang@126.com
}

\begin{abstract}
The purpose of this study was to provide a tool to detect NTLs and subsequently, discuss the establishment of a prepaid system in Cameroon. The conception of a prepayment system for electric power or other utility commodity distribution using Wi-Fi and GSM to store and transfer value (money or KWh, meters reading indexes) from the client module to cut-off module then to platform of the system and deliver power to the customer from the power distribution system. This system is also used as fraud detection model for the Cameroon National Electricity Company.
\end{abstract}

Keywords: Fraud Detection, Prepaid System, Meters, GSM, Non-Technical Losses

\section{Introduction}

Non-Technical Losses (NTLs) of energy in an electricity distribution system result from unregistered energy consumption. These losses result from energy theft or counting and profiling errors. In the electrical industry, knowledge on electricity consumers is important, as it provides an understanding of their consumption behaviour. With this knowledge, electricity suppliers can develop a new business strategy and offer services based on customer demand. One of the most commonly used methods of acquiring knowledge about customer behaviour is the load profile, which is defined as the electricity consumed by a customer or group of customers over a given period. Load profiles have been used for many years by utility companies for tariff formulation, system planning and marketing strategy development. Power companies record customer data histories, such as contract details, billing procedures and consumption indexes in various customer databases. However, the information that exists in the IT platform is often too complex to allow the human mind to make strategic and effective decisions or draw effective conclusions. In addition, this information is often inaccessible and takes a long time to retrieve, because of the problems associated with data archived in complex database systems.

Due to the NTL problems faced by electricity companies, different methods for an efficient management of NTLs in the electricity distribution sector have been proposed. The most effective method currently used to reduce NTLs is the use of smart electronic meters. However, although their installation is beneficial, their costs are high and new infrastructure is required for data collection. In this study, we provide a tool to detect NTLs and subsequently, discuss the establishment of a prepaid system in Cameroon at same moment.

\section{Electricity Sector in Cameroon}

Cameroon has a high exploitable hydroelectric potential of $19.7 \mathrm{GW}$, of which only $3.72 \%$ is currently being used as presented by Lekini et al. (2017). Electricity production has witnessed a steady growth from 2006 to 2016, despite a slight drop in 2009 and 2012. In addition, the commissioning of Emergency Thermal Power Plants in 2013 helped to increase electricity generation by $9.15 \%$ in 2013 compared to 2012. However, losses due to transmission, distribution and non-technical aspects have not ceased to increase from 2006 to 2016.

Cameroon plans to become an emerging country by 2035, which requires the development and consolidation of its industrial fabric. This requires adequate production and distribution of energy, considered essential for the smooth functioning of enterprises and the economy and for improving the living conditions of the population.

In this regard, Cameroon has enormous energy potential. In fact, its geographical location allows it to have the second highest hydroelectric potential of sub-Saharan Africa, after the Democratic Republic of the Congo.

This potential only needs to be used to meet an everincreasing demand and to reduce the imbalance that exists in this sector. Aware of this challenge, the authorities have launched an extensive program to increase the supply of electricity through the construction of several hydroelectric dams (the Lom-Pangar, Memve'ele and 
Mekin dams), the Kribi gas-fired power plant, boreholes for the production of thermal energy and even the exploitation of new and sustainable sources of energy.

The objective is not only to fill the national deficit, but also to export electricity. To absorb the energy deficit, in the same publication as presented by Lekini et al. (2017), Cameroon is engaged in several projects, such as:

- The Dibamba Power Developer Company, responsible for producing electricity from a thermal power plant with a capacity of $86 \mathrm{MW}$

- Construction of the reservoir dam of Lom Pangar in the Department of Lom and Djerem with a production capacity of $30 \mathrm{MW}$

- Construction of Memve'ele Hydroelectric Generating Station on Ntem in the Southern Region with a capacity of $201 \mathrm{MW}$
- Construction of the Mekin Hydroelectric Dam with a production capacity of $15 \mathrm{MW}$

- Construction of a gas-fired power plant in Kribi in the Ocean department, with a capacity of $216 \mathrm{MW}$, which is extendable to $300 \mathrm{MW}$

- The commissioning of the emergency thermal program through the installation of thermal power stations in the cities of Bamenda, Ebolowa, Mbalmayo and Yaoundé. These plants operate with light fuel oil and have a total capacity of $100 \mathrm{MW}$, i.e., $20 \mathrm{MW}$ in Bamenda, $10 \mathrm{MW}$ in Mbalmayo, 10 $\mathrm{MW}$ in Ebolowa and $60 \mathrm{MW}$ in Yaounde (Ahala)

The total demand and evolution between supply and demand are presented in Fig. 1 and 2.

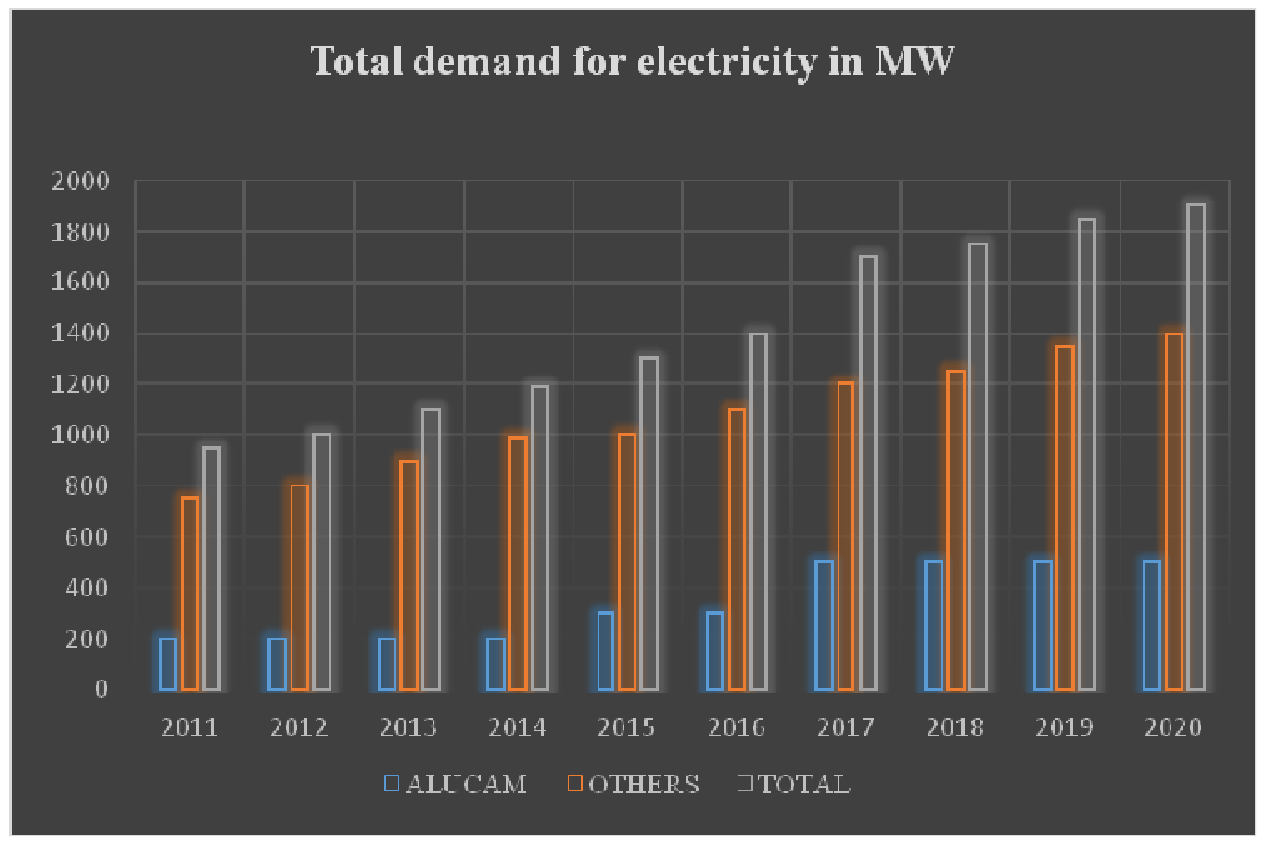

Fig. 1: Total demand for electricity in MW

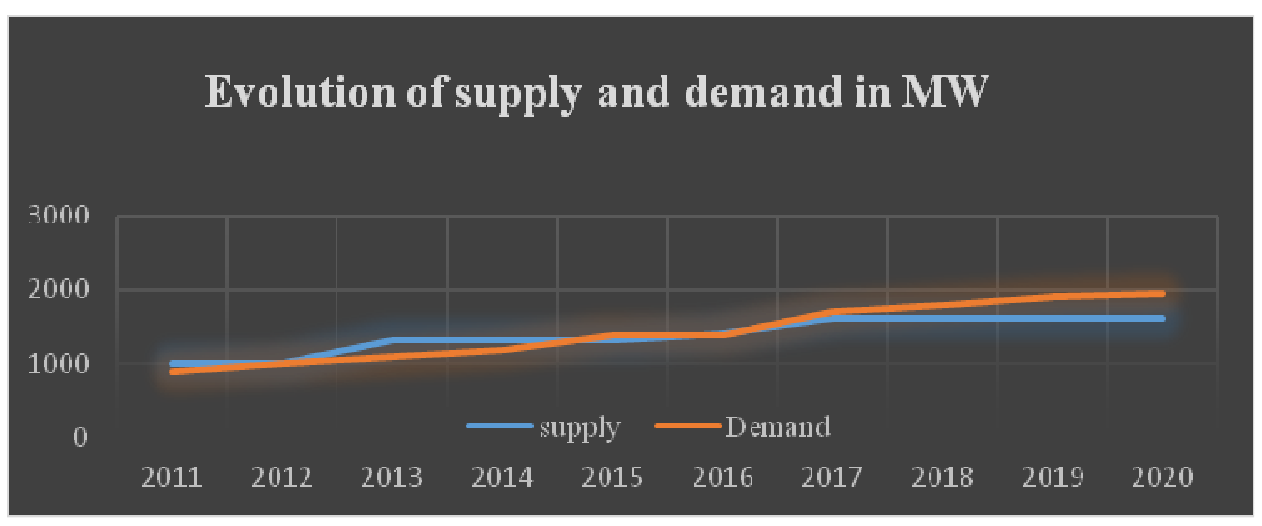

Fig. 2: Evolution of supply and demand in MW 


\section{Related Work and Literature Review}

The use of electronic token prepayment metering has been widely used in the UK for customers with poor payment record. Shwehdi and Jackson (1996) presented the Digital Tele-wattmeter System as an example of a microcontroller-based meter. The meter was implemented to transmit data on a monthly basis to a remote central office through a dedicated telephone line and a pair of modems; it was a stand-alone metering system.

Zhang et al. (1998) utilized a digital signal processor DSP-based meter to measure the electricity consumption of multiple users in a residential area. A Personal Computer (PC) at the control centre was used to send commands to a remote meter, which in turn transmitted data back using the power line communication technique. However, this system could not detect tampering by consumers.

Kwan et al. (2002) suggested a system design that can be used for data transmission between the PC and the smart card. The device transmits data in the half-duplex mode. They designed, modelled and simulated an intelligent prepaid energy meter using MATLAB/SIMULINK tools. Koay et al. (2003) designed and implemented a Bluetooth energy meter where several meters are in close proximity and communicated wirelessly with a master PC. Distance coverage is a major setback for this kind of system because Bluetooth technology works effectively only within a close range.

Scaradozzi and Conte (2003) viewed homeautomation systems as multiple agent systems. They proposed a home automation system whereby home appliances and devices are controlled and maintained for home management. However, this system does not measure the amount of energy consumed by users. Hong and Ning (2005) proposed the use of Automatic Meter Reading (AMR) using wireless networks. However, some commercial AMR products use the Internet for data transmission.

Stanescu et al. (2006) presented the design and implementation of SMS-based control for monitoring systems. They proposed three modules involving a sensing unit for monitoring complex applications. SMS is used for status reporting such as power failure. However, it does not consider issues related to billing systems for electricity board usage. Prepaid meters can also make use of state-of-art technologies such as WiMAX owing to the idea of centralized accounting, monitoring and charging. It brings telecommunication to the core of its activities to support more smart grid applications such as demand response and plug-in electric vehicles (Khan et al., 2007). Prepayment polyphase electricity metering systems have also been developedand consist of local prepayment and a card reader-based energy meter (Ling et al., 2010).
Malik et al. (2009) mainly focused on controlling home appliances remotely and providing security when the user is away, using SMS-based wireless home appliance control. Maheswari et al. (2009) aimed to develop an energy-efficient and low-cost solution for street lighting systems using the global system for mobile communication (GSM) and General Packet Radio Service (GPRS). The whole set-up enables the remote operator to turn off the lights when not required, regulate the voltage supplied to the streetlights and prepare daily reports on glowing hours.

Sharma and Shoeb (2011) suggested a method that utilizes telecommunication systems for automated transmission of data to facilitate bill generation at the server end as well as to the customer via SMS or Email. Amit and Mohnish (2011) suggested a prepaid energy meter that behaves like a prepaid mobile phone. The meter contains a prepaid card analogous to a mobile SIM card. The prepaid card communicates with the power utility using mobile communication infrastructure. Once the prepaid card is out of balance, the consumer load is disconnected from the utility supply by the contactor. The power utility can recharge the prepaid card remotely through mobile communication based on customer request.

Others factors contributing to NTLs activities such as:

- Unauthorized line tapping; tampering with meters so that meters record lower rates of consumption

- Unauthorized line diversions; stealing by bypassing meters or otherwise making illegal connections

- Inadequacies and inaccuracies of meter reading

- Inaccurate customer electricity billing

- Poor revenue collection techniques

- Arranging billing irregularities with the help of internal employees, such as making out lower bills and adjusting decimal point position on bills

- Non-payment of electricity bills

- Losses due to faulty meters and equipment

- Loss or damage of equipment/hardware that is, protective equipment, cables, conductors, switchgear etc

- Inaccurate estimation of non-metered supplies that is public lightning, agricultural consumption, rail traction etc

The below table gives us an overview of research carried out in this area between 1953 and 2017 as presented in Table 1.

\section{Methodology for the Design of a Prepaid System for NTLs}

In this part, we present the prototype allowing us to eradicate the PNT in the Cameroonian electricity network as presented in Fig. 3. 
Table 1: Overview of research carried out in this area between 1953 and 2017

\begin{tabular}{|c|c|c|}
\hline Years & Authors & Titles \\
\hline$\overline{1953}$ & Courant and Hilbert (2008) & Methods of mathematical physics \\
\hline 1979 & Vapnik and Chervonenkis (1974) & Theory of pattern recognition \\
\hline 1982 & Devijver and Kittler (1982) & Pattern recognition: A statistical approach \\
\hline 1987 & Fletcher (2013) & Practical methods of optimization \\
\hline 1992 & Birch and Ozveren (1992) & An adaptive classification for tariff selection \\
\hline 1993 & Fisher et al. (1993) & Applying AI clustering to engineering tasks \\
\hline \multirow[t]{3}{*}{1995} & Vapnik (1997) & The nature of statistical learning theory \\
\hline & Kohavi (1995) & A study of cross-validation and bootstrap for accuracy estimation and model selection \\
\hline & Benjamini and Hochberg (1995) & controlling the false discovery rate: A practical and powerful approach to multiple testing \\
\hline 1996 & Benessahraoui (1996) & Le contrôle des pertes non techniques d'électricité \\
\hline \multirow[t]{2}{*}{1997} & Scholkopf (1997) & Support vector learning \\
\hline & Friedman (1997) & Knowledge discovery and data mining \\
\hline 1998 & Brossette et al. (1998) & $\begin{array}{l}\text { Association rules and data mining in hospital infection control and public } \\
\text { health surveillance }\end{array}$ \\
\hline \multirow[t]{6}{*}{1999} & Lavrac (1999) & Selected techniques for data mining in medicine \\
\hline & Platt (1999) & Fast training of support vector machines using sequential minimal optimization \\
\hline & Karypis et al. (1999) & Chameleon: Hierarchical clustering using dynamic modeling \\
\hline & Ray and Turi (2000) & $\begin{array}{l}\text { Determination of number of clusters in k-means clustering and application in color } \\
\text { image segmentation }\end{array}$ \\
\hline & Bjornar and Chinatsu (1999) & Fast and effective text mining using linear- time document clustering \\
\hline & Chen et al. (1999) & Implementation of the load survey system in taipower \\
\hline 2000 & Steinbach et al. (2000) & A comparison of document clustering techniques \\
\hline 2001 & Halkidi et al. (2001) & On clustering validation techniques \\
\hline \multirow[t]{2}{*}{2002} & Han and Kamber (2012) & « Data mining: Concepts and techniques \\
\hline & Zakaria and Lo (2002) & Load profiling in the new electricity market \\
\hline \multirow[t]{2}{*}{2003} & Maulik and Bandyopadhyay (2002) & Performance evaluation of some clustering algorithms and validity indices \\
\hline & Chang and Lu (2003) & Load profiling and its applications in power market \\
\hline \multirow[t]{7}{*}{2004} & Duarte et al. (2003) & Data mining techniques applied to electric energy consumers characterization \\
\hline & Chang and Lu (2003) & Load profiling and its applications in power market \\
\hline & Duarte et al. (2003) & Data mining techniques applied to electric energy consumers characterization \\
\hline & Gerbec et al. (2003) & « Determination and allocation of typical load profiles to the eligible consumers \\
\hline & Markou and Singh (2003) & Novelty detection: A review - Part 1: Statistical approaches \\
\hline & Ghajar and Khalife (2003) & $\begin{array}{l}\text { Cost/Benefit analysis of an AMR system to reduce electricity theft and maximize } \\
\text { revenues for electricite du liban }\end{array}$ \\
\hline & Gerbec et al. (2004) & $\begin{array}{l}\text { Determining the load profiles of consumers based on fuzzy logic and probability } \\
\text { neural networks }\end{array}$ \\
\hline \multirow[t]{20}{*}{2005} & Lo and Zakaria (2004) & Electricity consumer classification using artificial intelligence \\
\hline & Verdu et al. (2004) & $\begin{array}{l}\text { Characterization and identification of electrical customers through the use of } \\
\text { self-organizing maps and daily load parameters }\end{array}$ \\
\hline & Smith (2004) & Electricity theft: A comparative analysis \\
\hline & Fourie and Calmeyer (2004) & $\begin{array}{l}\text { A statistical method to minimize electrical energy losses in a local electricity } \\
\text { distribution network }\end{array}$ \\
\hline & Filho et al. (2004) & Fraud identification in electricity company customers using decision tree \\
\hline & Doorduin et al. (2004) & «Feasibility study of electricity theft detection using mobile remote check meters \\
\hline & Kou et al. (2004) & Survey of fraud detection techniques \\
\hline & Ren et al. (2004a) & RDF: A density-based outlier detection method using vertical data representation \\
\hline & Ren et al. (2004b) & A vertical outlier detection algorithm with clusters as by-product \\
\hline & Cabral et al. (2004) & Fraud detection in electrical energy consumers using rough sets \\
\hline & Hodge and Austin (2004) & A survey of outlier detection methodologies \\
\hline & Gerbec et al. (2005b) & Allocation of the load profiles to consumers using probabilistic neural networks \\
\hline & Chicco et al. (2005) & Emergent electricity customer classification \\
\hline & Figueiredo et al. (2005) & An electric energy consumer characterization framework based on data mining techniques \\
\hline & Gerbec et al. (2005b) & Allocation of the load profiles to consumers using probabilistic neural networks \\
\hline & Chicco et al. (2005) & Emergent electricity customer classification \\
\hline & Figueiredo et al. (2005) & An electric energy consumer characterization framework based on data mining techniques \\
\hline & Yao and Steemers (2005) & A method of formulating energy load profile for domestic buildings in the UK \\
\hline & Espinoza et al. (2005) & $\begin{array}{l}\text { Short-term load forecasting, profile identification and customer segmentation: A } \\
\text { methodology based on periodic time series }\end{array}$ \\
\hline & Gerbec et al. (2005a) & Actual load profiles of consumers without real time metering \\
\hline
\end{tabular}


Table 1: Continue

Lozano and Acufia, (2005)

2006 Nizar et al. (2006a)

2009 Mabrouka (2009)

Birch and Ozveren (1992)

Mathias (2009)

2010c Nagi et al. (2010c)

2012 Rengarajan and Loganathan (2012)

2013 Sheriff and Maguire (2013)

2014 Creedy (2014)

Dangar and Joshi (2014b)

Dangar and Joshi (2014a)

Christopher et al. (2014)

2015 Sahoo et al. (2015)

Zhou and Chen (2015)

2016 Glauner et al. (2016)

2017 Lekini et al. (2017)
Parallel algorithms for distance-based and density-based outliers

Load profiling method in detecting non-technical loss activities in a power utility

Caractérisation aveugle de la courbe de charge électrique: Détection, classification et estimation des usages dans les secteurs résidentiel et tertiaire

An adaptive classification for tariff selection

Perte d'énergie dans les réseaux de distribution d'électricité

NTL detection of electricity theft and abnormalities for large power consumers in TNB Malaysia

Power theft prevention and power quality improvement using fuzzy logic

Ranking distribution of environmental outcomes across population groups

Interpreting inequality measures and changes in inequality

Normalization based K means Clustering Algorithm

Electricity theft detection techniques for distribution system in GUVNL

Distribution line monitoring system for the detection of power theft using power line communication

Electricity theft detection using smart meter data

A dynamic programming algorithm for leveraging probabilistic detection of energy theft in smart home

The challenge of non-technical loss detection using artificial intelligence: A survey Evaluation of customer behaviour irregularities in cameroon electricity network using support vector machine

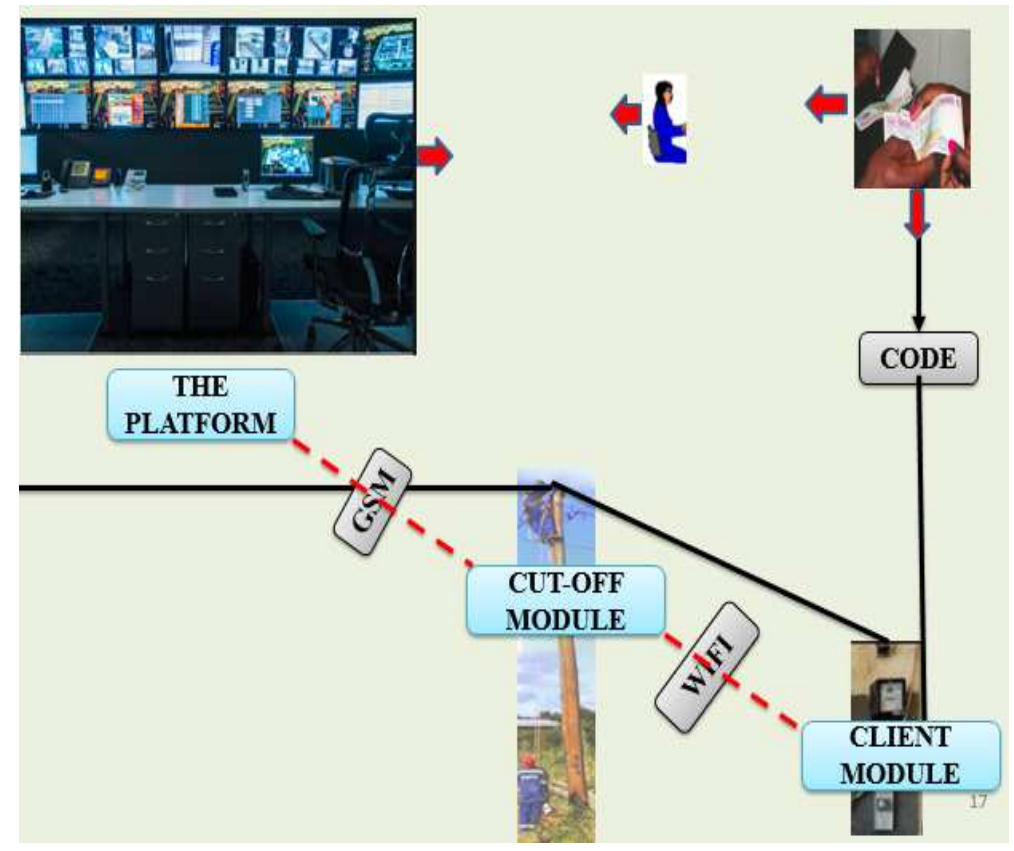

Fig. 3: Prototype design

\section{How does the System Work?}

- The user enters a code corresponding to the amount of energy he wants to consume. After validating the code, the system gives the user access to the network, measures the customer's consumption and puts the customer off the grid once the energy consumed is equal to the energy purchased

- The prototype to be designed consists of an electronic module installed on the meter, an electronic module installed at the pole on which the customer is connected and a customer management platform

- The module installed on the meter reads the customer's consumption and communicates it to the module on the pole to which the customer is connected. This module also allows the charging and display of the payment procedure

- The module on the pole has the role of evaluating the consumption at the post, acting on the cut and inform the platform on the consumption at the pole 
and consumption at the meter. In the case where consumption at the pole is greater than consumption at the client meter the system detects fraud and the customer is cut off

\section{Description of the System Modules}

The system of prepaid billing and computer monitoring of real-time consumption of customers in its most general view is one that combines several resources available and easily mobilized. In our case, we have a prepaid meter installed at the customer, a cut-off module installed on the electricity pole closest to the meter and a platform.

\section{Module Installed at the Client}

The customer's electricity meter measures energy consumption and compares it with prepaid energy. This prepaid counter consists of a display screen, an alphanumeric keyboard, a wireless communication module and a metering and consumption evaluation system. As presented in Table 2.

\section{Module Installed on the Electric Pole}

The cut-off module receives the customer's consumption and the cut-off order coming from the prepaid meter installed on the customer's premises via the Wi-Fi. It acts on the line disconnector when the cutoff is activated. This module also counts the electrical energy that passes through the pole to the customer. Electrical energy consumption at the customer and consumption at the pole are transferred by GSM to the control platform.

The set allows us to detect fraud, compare consumption at the customer level and at the pole. As presented in Table 3.

\section{The Platform}

The role of the platform is to generate customer codes and decodings, but also to receive, store and process the data transmitted by the module installed on the pole.

\section{Generating the Recharging Code}

For the generation of the recharge code we need to:

- The volume of consumption

- The number of the meter

- A serial number

The volume of consumption kilowatt hours of charging is defined according to the cost per kilowatt hour when purchasing the code number.

The number of the counter that associates the generated number has a single counter

A serial number is a number which is incremented with each new invoice. Thus each invoice is unique. This ensures that a recharge code is only used once.

NOTE: The meter number and the unique identifier ensure that a code is used only once on a meter. Its three pieces of information that are combined and then encrypted with a key that is kept private.

For encryption, we can use proven algorithms such as AES which is 128-bit encrypted and DES which is 64-bit encrypted.

This would ensure that the code structure remains protected. So without the encryption key, it is very difficult to generate a valid code. As presented in Fig. 4.

\section{Decoding the Recharge Code}

After reading the code by the device set up, it is to decipher by the same algorithm used for coding with the same key used this time for decryption. This key is stored in the device's memory and after decoding we can extract:

- The volume of consumption stored in the code

- The number of the meter for which the code is intended

- The unique number associated with the code

Table 2: Client modules

\begin{tabular}{|c|c|c|}
\hline Module & Constituents & Role \\
\hline Prepaid counter & $\begin{array}{l}\text { Supply circuit } \\
\text { Module for acquiring data related } \\
\text { to the reading of client indexes } \\
\text { Client-counter communication interface } \\
\text { Communication interface with the } \\
\text { cutoff module }\end{array}$ & $\begin{array}{l}\text { Adjust the voltage level across the electrical components of the system. } \\
\text { Extract the customer's electricity consumption from the meter. } \\
\text { Allow code entry and display of the charging procedure. } \\
\text { Transfer consumption and cut-off order. }\end{array}$ \\
\hline & ale & \\
\hline Module & Constituents & Roles \\
\hline Cut-off module & $\begin{array}{l}\text { Supply circuit } \\
\text { Module reading indexes on the pole. } \\
\text { Communication module with the prepaid } \\
\text { counter (transfer of customer indexes) } \\
\text { Communication module with the platform } \\
\text { Cutoff circuit }\end{array}$ & $\begin{array}{l}\text { Adjust the voltage level across the electrical components of the system. } \\
\text { Allows reading of the indexes on the column. } \\
\text { Receive consumption and cut-off order. } \\
\text { Transfer the data to the platform. } \\
\text { Act on the line disconnector. }\end{array}$ \\
\hline
\end{tabular}




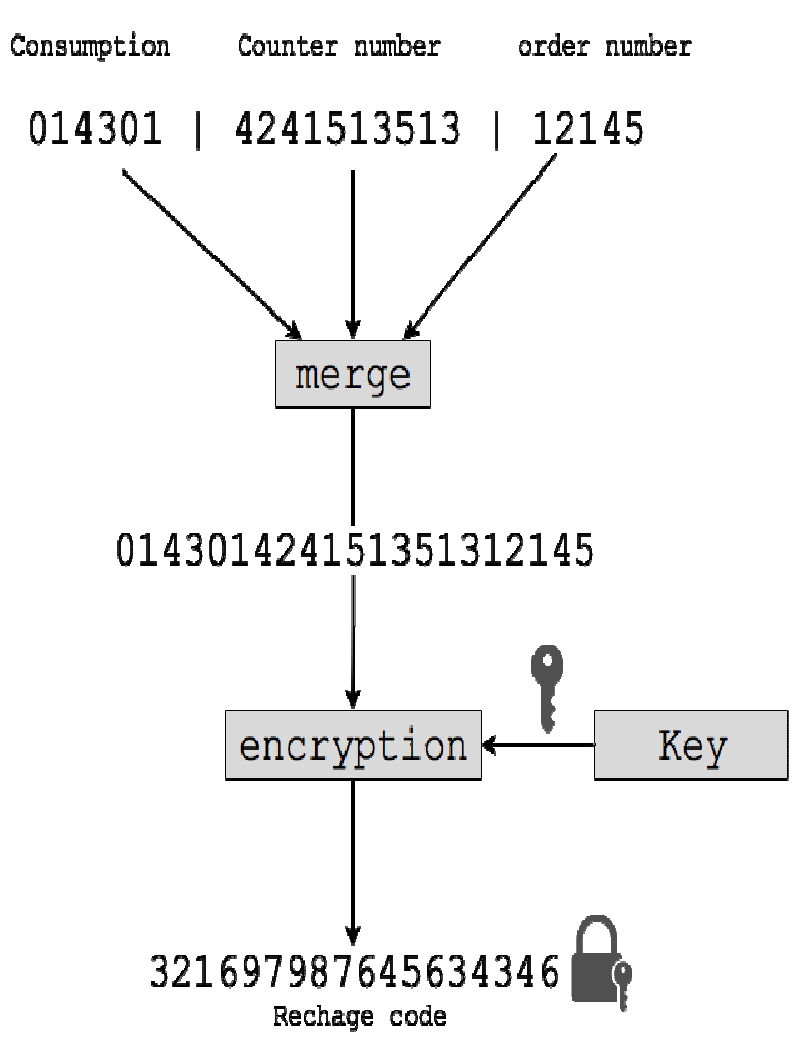

Fig. 4: Generating the recharge code

But before you save some checks are done:

- We check if the unique code already registered by the device prevents the same code from being used several times

- It is checked whether the number of the counter present in the code corresponds to that of the counter which was previously registered in the device

If one of the checks fails the code will be rejected by the device.

If against this one is passed all the checks, the code is considered valid. The volume of consumption present in the code is recorded in the device which will decrement it as the meter records the consumption until it is zero and the power supply is cut off.

In order to prevent the code from being used a second time, the unique code is saved. So this code recharge will not pass the verification because the device remembers that he has already seen. As presented in Fig. 5.

\section{List of Materials to Use}

The material needed for the realization of our prototype is given in the Table 4.

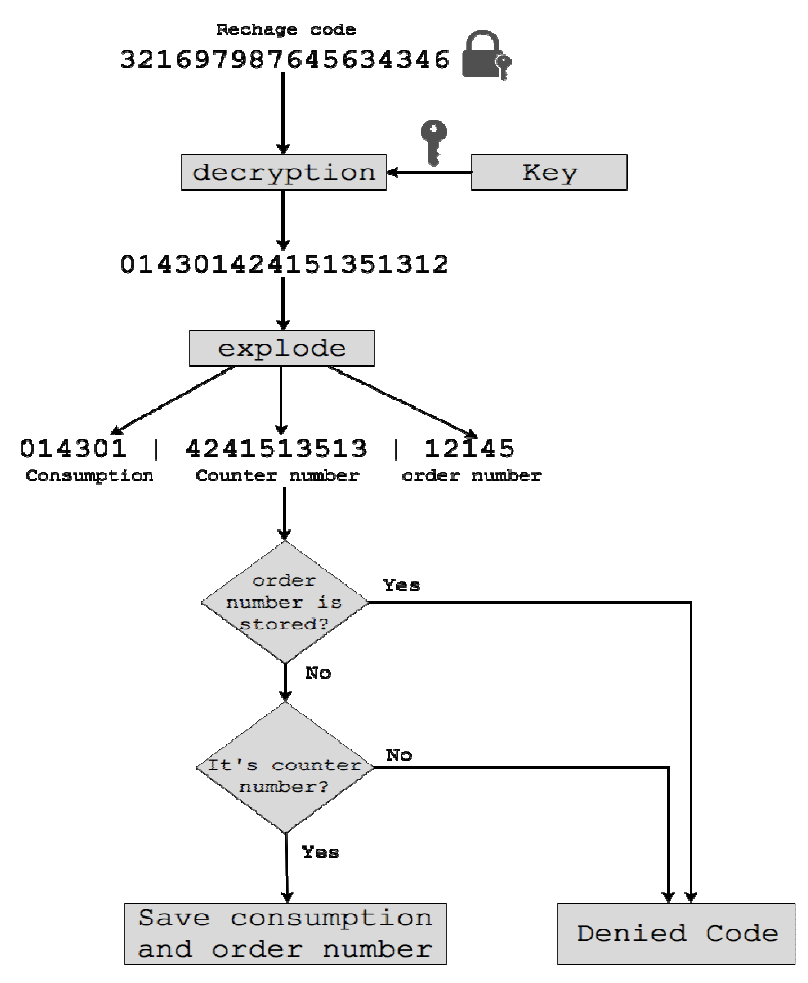

Fig. 5: Decodings the recharge code

Table 4: List of equipment used to implement prototype

\begin{tabular}{lc}
\hline Materials & Quantity \\
\hline Arduino Uno R3 card & 2 \\
5V Relay module & 2 \\
WiFi module & 2 \\
Plexiglass support & 2 \\
Connection Cable Pack & 2 \\
Test plate & 5 \\
LCD screen $20^{*} 4$ & 1 \\
Photoresistor & 5 \\
Pack de Resistor & 1 \\
Terminals & 10 \\
Transformer220/12 & 2 \\
Digital meter & 2 \\
Drawing-board & 2 \\
GSM module A6 & 2 \\
Numeric keyboard & 1 \\
1000u Capacitor & 4 \\
Graetz Bridge & 4 \\
Transistor 2N2222 & 4 \\
Regulator 5V & 4 \\
\hline
\end{tabular}

\section{Circuit Diagrams of Modules}

\section{Communication Module}

The communication module exists for the client module only for the module cut, as such we have: Communication interface with the cutoff module Communication module with the prepaid counter as presented in Fig. 6. 




Fig. 6: Sub communication module between the cutoff module and the customer meter

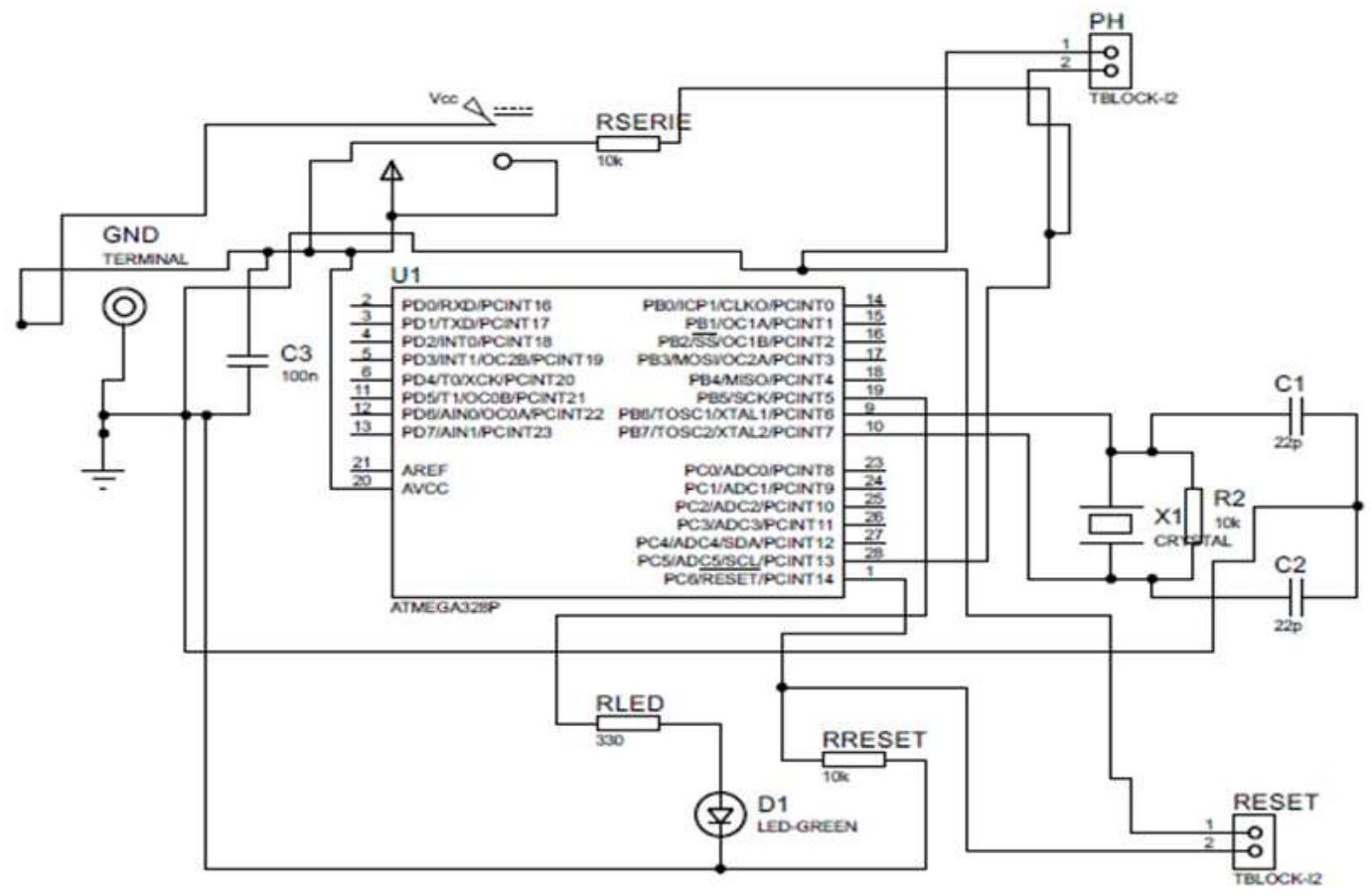

Fig. 7: Sub indexes reading module on customer and pole meters

Its role is to transfer indexes related to the customer's consumption but also to act on the order of cut in case of fraud or insufficient credit in the customer account. The design is presented in Fig. 8.

\section{Indexes Reading Module}

The indexes reading module of the meter installed at as well as that installed on the post is given by the diagram of Fig. 7. 


\section{Screen for Entering Codes}

For the acquisition of data related to the recharge of the consumption of the customer we have designed the diagram presented in Fig. 8 and 9.

\section{Le Wi-Fi Module or Esp8266 Module}

The ESP8266 module is a grouping of multiple components, in the form of a mini-electronic board, with 8 connection pins as presented in Fig. 10.


\section{ШШШ \\ IIIIIIII}

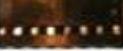

Fig. 8: Sub code entry module and recharging procedure

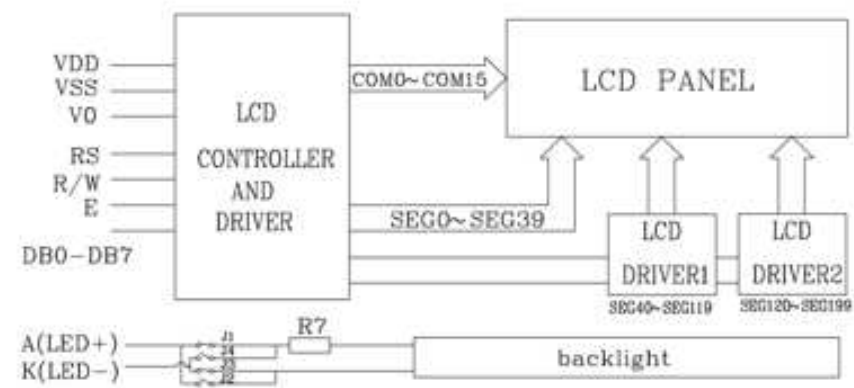

\begin{tabular}{|c|c|c|c|}
\hline $\begin{array}{l}\text { Pin } \\
\text { no. }\end{array}$ & Symbol & $\begin{array}{c}\text { External } \\
\text { connection }\end{array}$ & Function \\
\hline 1 & $V_{\text {sis }}$ & \multirow{3}{*}{ Power supply } & Signal ground for LCM (GND) \\
\hline 2 & $V_{00}$ & & Power supply for logic ( $+5 \mathrm{~V})$ for LCM \\
\hline 3 & $V_{0}$ & & Contrast adjust \\
\hline 4 & RS & MPU & Register select signal \\
\hline 5 & RWW & MPU & Read/write select signal \\
\hline 6 & $E$ & MPU & Operation (data read/write) enable signal \\
\hline $7 \sim 10$ & DBO-DB3 & MPU & $\begin{array}{l}\text { Four low order bi-directional three-state data bus lines. } \\
\text { Used for data transter between the MPU and the LCM. } \\
\text { These four are not used during 4-bit operation. }\end{array}$ \\
\hline $11-14$ & DB4-DB7 & MPU & $\begin{array}{l}\text { Four high order bi-directional three-state data bus lines. } \\
\text { Used for data transter between the MPU }\end{array}$ \\
\hline 15 & LED+ & \multirow{2}{*}{$\begin{array}{l}\text { LED BKL power } \\
\text { Supply }\end{array}$} & Power supply for BKL $(V=+5.0 \mathrm{~V})$ \\
\hline 16 & LED- & & Power supply for BKL (GND) \\
\hline
\end{tabular}

Fig. 9: Data acquisition screen 


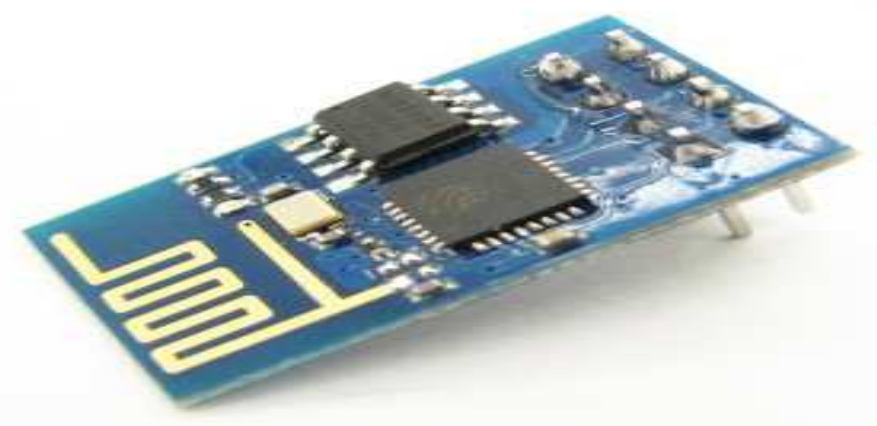

Fig. 10: ESP 8266

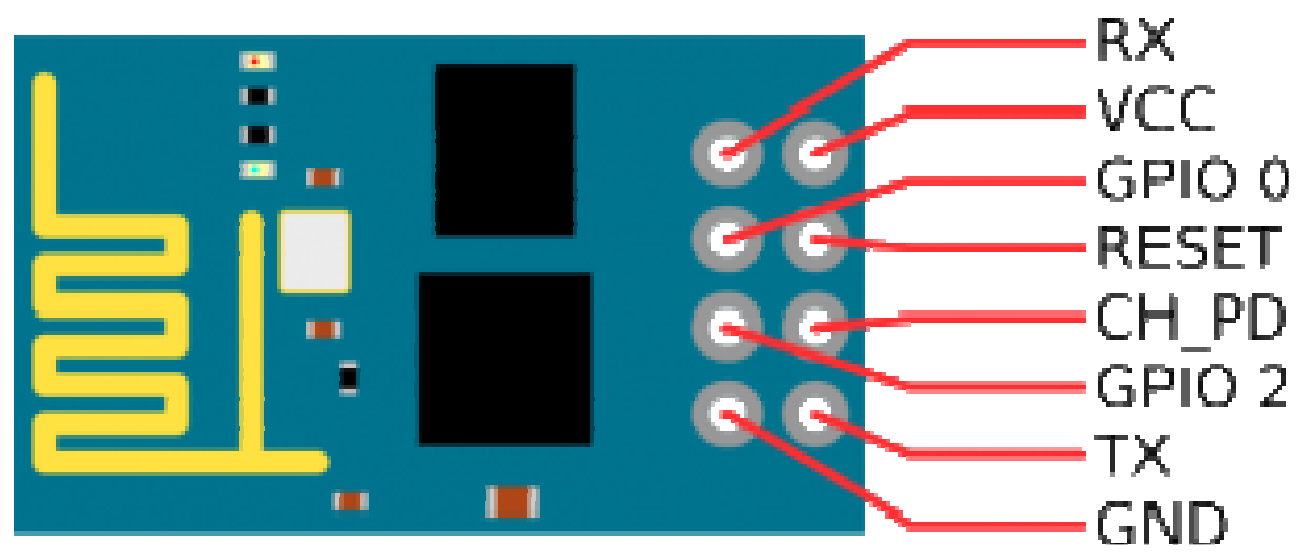

Fig. 11: Sub Wifi module

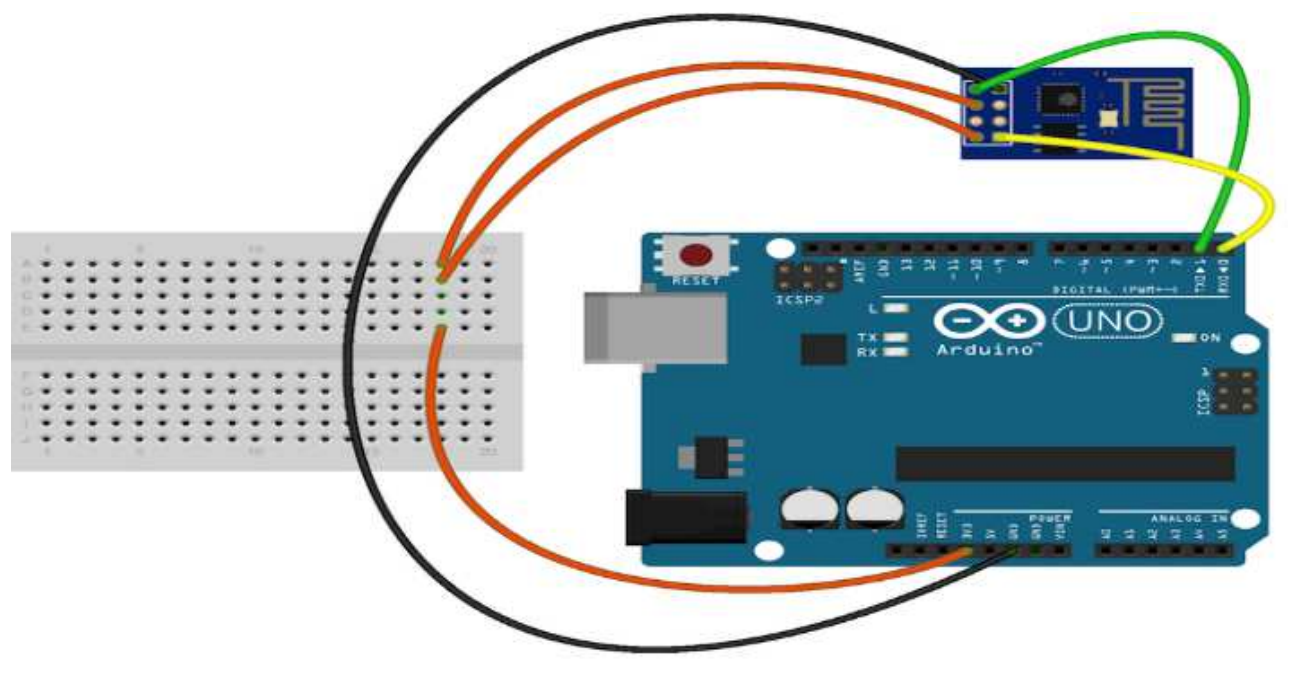

fritzing

Fig. 12: Connexion du module Wifi 


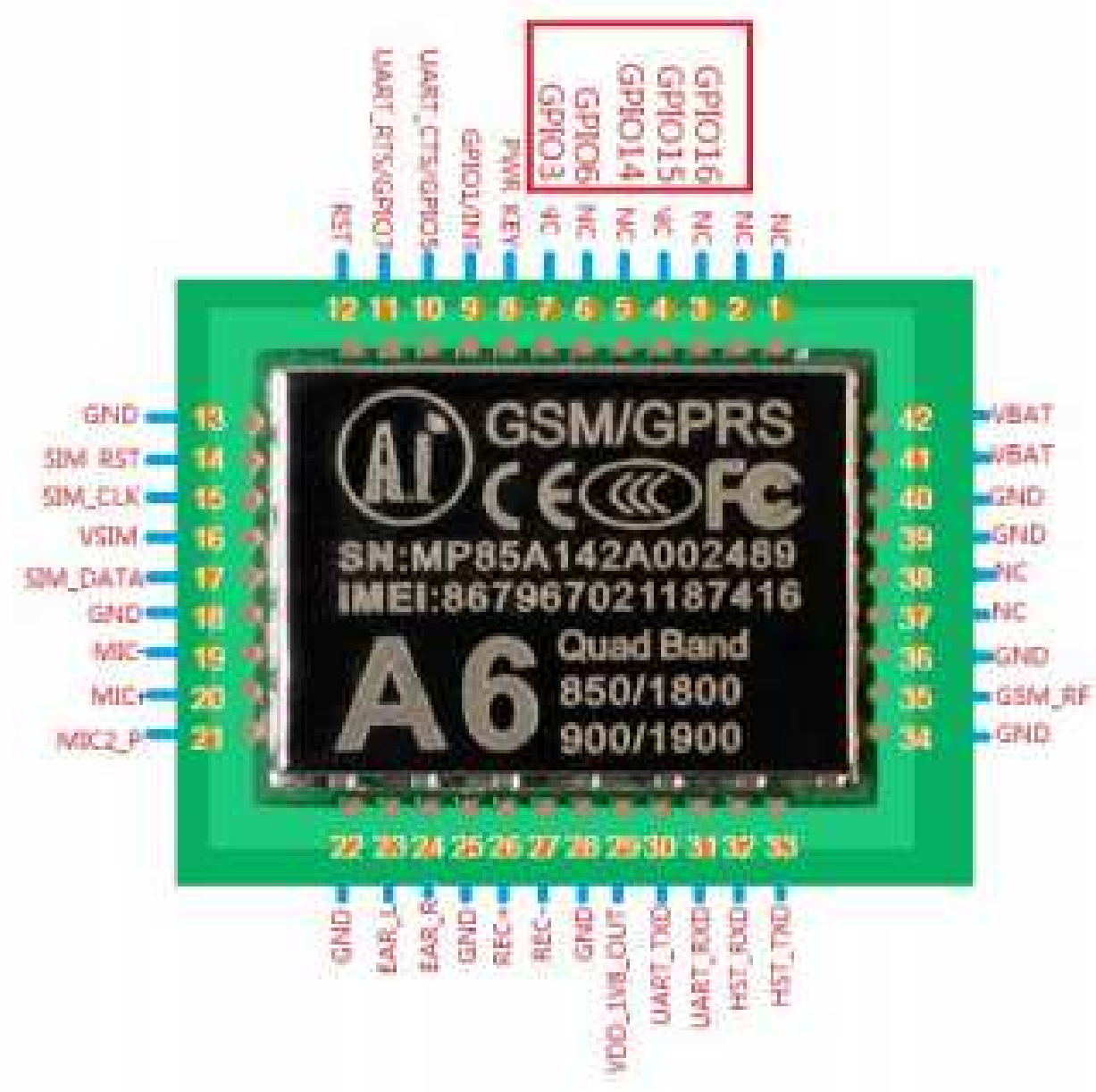

Fig. 13: Diagram of the pins of the GSM modem A6

This module measures $2.5 \times 1.5 \mathrm{~cm}$ and allows you to connect to a Wi-Fi point to communicate in client/server mode (be client or server) but it can also be defined as a Wi-fi point. The details of the connections are given in Fig. 11 and the design is presented in Fig. 12.

- UTXD: This is the output of the ESP8266 data. This signal will be $3.3 \mathrm{~V}$ and will be easily recognized by the Arduino, without the need for a logical level conversion

- CH_PD ("chip power down"): Must be at 3.3 volts to allow operation of the module

- RST ("reset"): When this pin is connected to ground, this results in a reset (restart) of the module

- Vcc: Power supply of the module: $3.3 \mathrm{~V}$

- GND: Ground

- GPIO2: "General Purpose Input Output"

- GPIO0: Set to 3.3 volts in normal use (connected to GND when you want to update the firmware of the ESP8266)

- URXD: Data entry, which must be at a logic level of 3.3 volts

\section{GSM Module}

The communication between the cutoff module and the computer platform will be done through a GSM modem A6 whose is presented in Fig. 13.

GSM: Global System for Mobile Communication (GSM) (historically "Mobile Special Group") is a second-generation digital standard for mobile telephony. GSM is the most used standard in Europe at the end of the 20th century, supported in the United States. This standard uses the $0.9 \mathrm{GHz}$ frequency band in Europe. In the United States, however, the frequency band used is the $1.9 \mathrm{GHz}$ band. For example, mobile phones that can operate in both Europe and the United States.

In a GSM network, the user's terminal is called a mobile station. A mobile station, in this case, a GSM modem, is composed of a Subscriber Identity Module (SIM) card, enabling the uniquely identifiable use of a mobile terminal.

Terminals (devices) are identified by a unique 15digit identification number called International Mobile Equipment Identity (IMEI). This code can be protected using a 4-digit key called PIN code. 
The SIM card thus makes it possible to identify each user, independently of the terminal used during the communication.

The GSM modem is actually an integrated circuit with the ability to communicate with a GSM antenna and a SIM card (called a chip by misuse of language), thanks to certain commands that can come from a microcontroller or a PC.

GSM has the advantage of being not only far-reaching (several kilometers), to have a wide geographical coverage, but also to be wireless, so flexible.

The operating principle is given by the Fig. 14 .

\section{Cut Off Circuit Module}

The cut-off circuit makes it possible to act on the customer's electrical power supply line by cutting or not through a controlled relay.

The electromagnetic relay consists of a multi-coil tower, wound on an iron core, to form an electromagnet. When the coil is excited, by the current flowing through it, the core becomes temporarily magnetized. The magnetized core attracts the iron frame. The articulated armature operates one or more sets of contacts. When the coil is de-energized the armature and contacts are released. The relay can generate a very high voltage across the coil when it is turned off. This can damage other components in the circuit. To avoid this, a so-called freewheel diode is connected across the coil. The Relay has five points. On both operating points one is permanently connected to the 5 DC power source and the other point is connected to the collector section of the power transistor. When the power transistor is saturated, that is to say the coil of the excited relay, it is magnetized and attracts the iron frame. The iron plate moves from the Normally Connected position (NC) to the Normally Open position (NO).
Thus, the line disconnector closes and allows the passage of electrical energy. When a fraud is detected or prepaid energy consumption is reached, the disconnector opens and prevents the passage of electrical energy.

Its module is presented in Fig. 15 and 16.

\section{Counter Module}

It is given by the following diagram presented in Fig. 17.

\section{Power Module}

It is present in the customer and pole modules and its role is to adapt the voltage level to the terminals of the electrical components of the system his design is presented in Fig. 18.

\section{Overview of the Prototype}

After presenting the various modules and submodules and their roles, we present in Fig. 19 the overall diagram of our prototype.

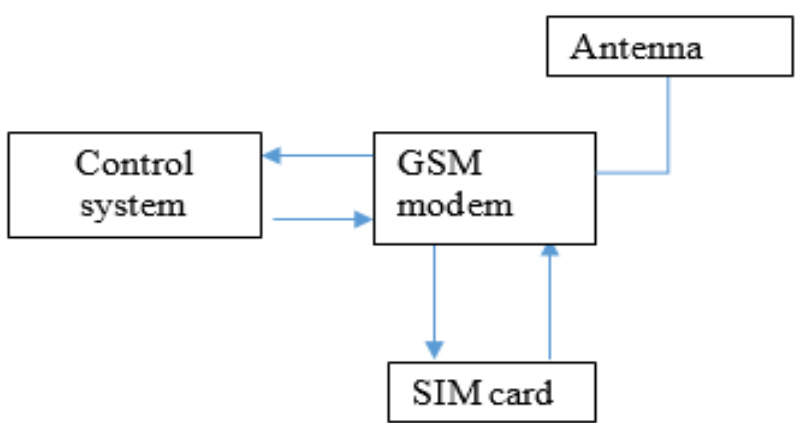

Fig. 14: The general operation of a GSM modem

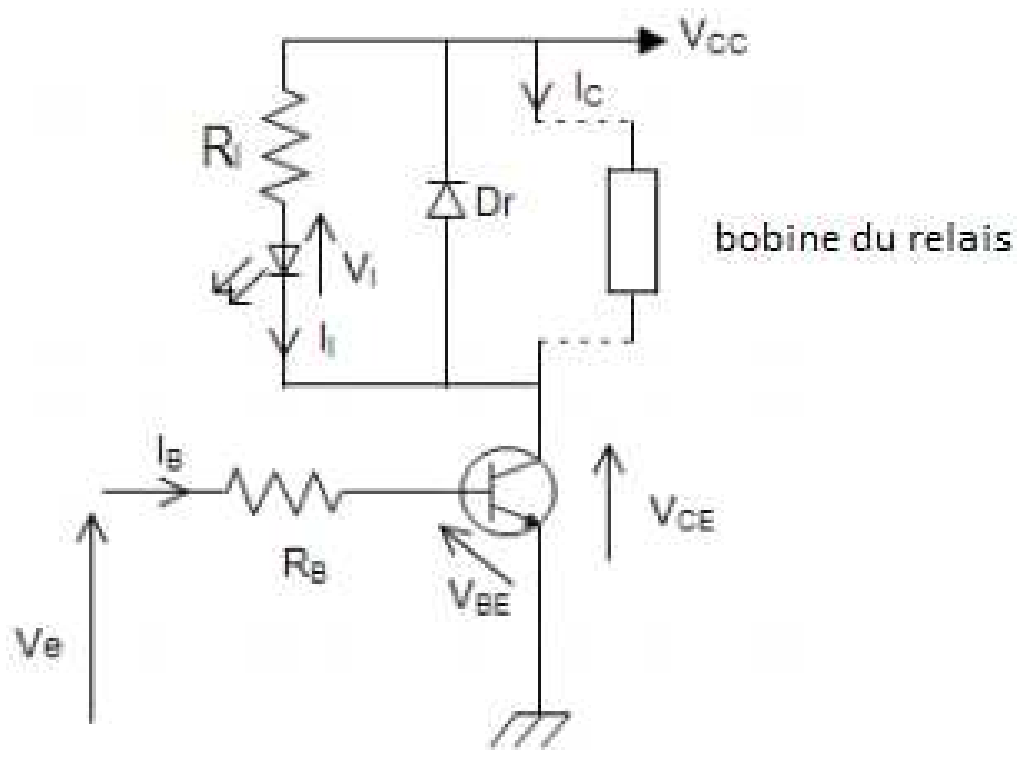

Fig. 15: Control diagram of the cutoff circuit 


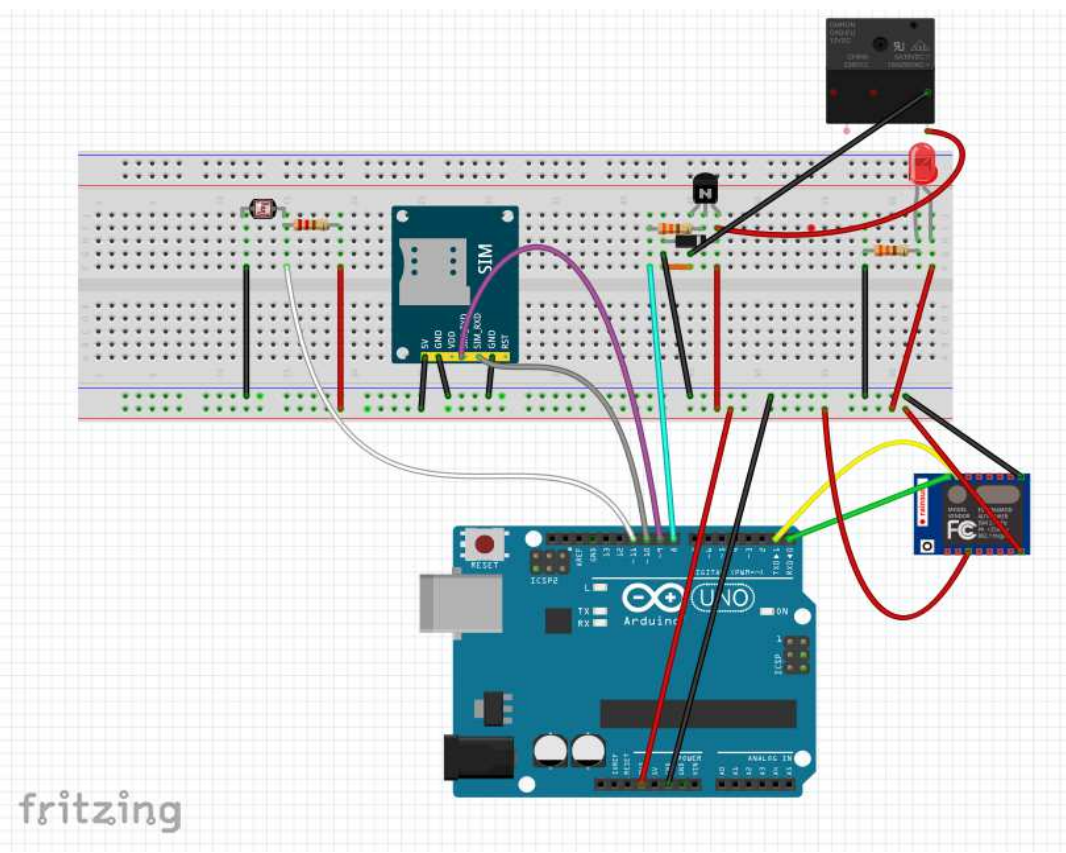

Fig. 16: Cutoff module representation

$$
\text { trifs!na }
$$



Fig. 17: Counter module representation



Fig. 18: Electrical diagram of the supply circuit 


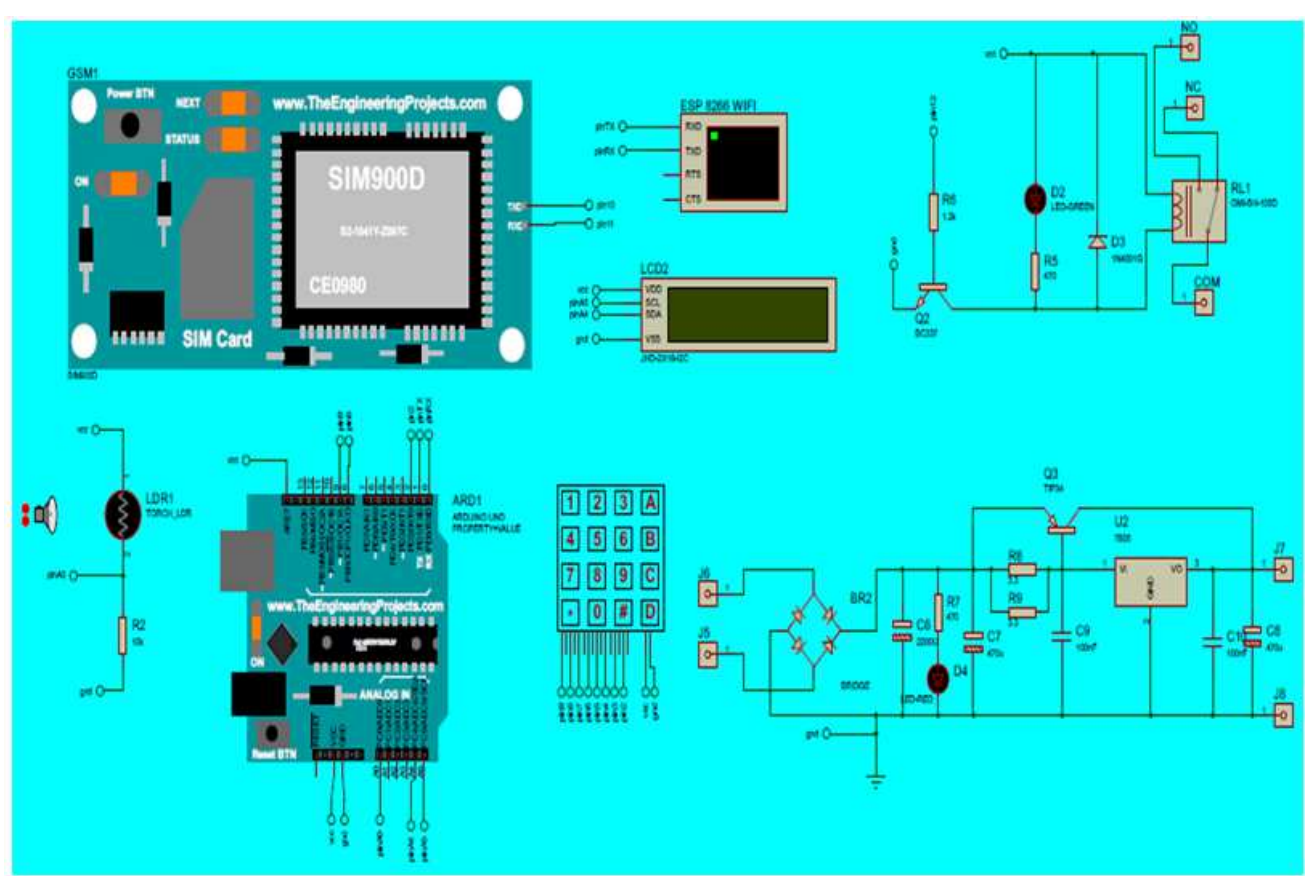

Fig. 19: Overall electrical diagram of our prototype

\section{Results and Discussion}

\section{Results}

In this part we present our prototype, we have from the left to the right the client module and the cutoff module and down, we have the different screens of our platform: the home screen, the generation codes screen and the control screen as presented in Fig. 20. Our prototype brings several answers for the eradication of the nontechnical losses in the Cameroonian electricity network namely:

- Cost of meter readings

- Lack of access to meters

- Cash delay problem

- Litigation management

- Losses on non-payments

- More unpaid bills from tenants

Because it makes it possible to do remote metering, the management of the flows of consumption, the control of the consumptions and increase of the invoicing rate of the company in charge of the distribution but also a huge gain in terms of energy to $10 \%$ of the total production of Cameroon in 2020 is $300 \mathrm{MW}$. This result is obtained on the combining of the work of this research with those carried out in our previous works on the Evaluation of Customer Behaviour Irregularities in Cameroon Electricity Network using Support Vector Machine published in American Journal of Engineering and Applied Sciences in 2017.
Table 5: Evaluation of MW cost in cameroon

\begin{tabular}{lll}
\hline Projects & Power in MW & Cost (Billions) \\
\hline Memvele & 200 & 503 \\
Hydromekin & 15 & 25 \\
Lom pangar & 30 & 500 \\
Natchigal & 420 & 690 \\
Makay & 350 & 500 \\
Nyong power H & 250 & 500 \\
Song ndong & 270 & 375 \\
Total & 1535 & 3093 \\
Cost of MW & 2 & Billion Xaf \\
\hline
\end{tabular}

Knowing that the MW of energy produced is evaluated as follows in Table 5, our prototype allows a gain in terms of investment in the order of 600 billion CFA Franc.

\section{Discussions}

The work carried out in this research gives satisfactory results because it allows to detect and eradicate non-technical losses in electricity however some electrical power losses are inevitable, steps can be taken to ensure that it is minimized. Several measures have been applied to eradicate, including those based on technology and those that rely on human effort and ingenuity the overview of several research done concerning this topic are presented in Table 6.

Given the importance of electricity in the socioeconomic development of populations, its key role in the fight against poverty and its accessibility to all, management, economy and the reliability of innovation in its recovery are a priority. If prepayment attempts to meet this priority, its practical exploitation presents deficiencies on both sides. 




Control panel

\begin{tabular}{|c|c|c|c|c|c|c|}
\hline \multicolumn{7}{|c|}{ History } \\
\hline Status & Date Time & Client Name & Registration number & Counter Index & Electric pole Index & Margin \\
\hline FRAUD & $11 / 16 / 201710 \mathrm{~h} 59 \mathrm{~m}$ & Lekini & 12345 & $1.25 \mathrm{Wh}$ & $73.75 \mathrm{Wh}$ & $72.5 \mathrm{Wh}$ \\
\hline FRAUD & 11/16/2017 10h 58m & Lekini & 12345 & $1.25 \mathrm{Wh}$ & $73.75 \mathrm{Wh}$ & $72.5 \mathrm{Wh}$ \\
\hline FRAUD & 11/16/2017 10h 56m & Lekini & 12345 & $1.25 \mathrm{Wh}$ & $73.75 \mathrm{Wh}$ & $72.5 \mathrm{Wh}$ \\
\hline
\end{tabular}

Fig. 20: Prototype

Table 6: Overview of relative works

\begin{tabular}{|c|c|c|c|c|}
\hline Authors & Publication titles & Model used & Number of customers & Accuracy \\
\hline Cabral et al. (2009) & $\begin{array}{l}\text { Fraud detection system for high and low } \\
\text { voltage electricity consumers based on } \\
\text { data mining. Power and Energy Society } \\
\text { General Meeting (PES'09). }\end{array}$ & SOM & $2 \mathrm{~K}$ & 0.93 \\
\hline Costa et al. (2013) & $\begin{array}{l}\text { Fraud detection in electric power } \\
\text { distribution networks using an ANN } \\
\text { based knowledge-discovery process. } \\
\text { Int. J. Artificial Intelligence Applic. }\end{array}$ & $\mathrm{NN}$ & $22 \mathrm{~K}$ & 0.87 \\
\hline \multirow[t]{4}{*}{ Depuru et al. (2011) } & Support vector machine based data & SVM (Gauss) & 1350 & 0.98 \\
\hline & classification for detection of electricity & Bool rules & $700 \mathrm{~K}$ & 0.47 \\
\hline & theft", Power Systems Conference and & Fuzzy rules & $700 \mathrm{~K}$ & 0.55 \\
\hline & Exposition (PSCE), 2011. & SVM linear & $700 \mathrm{~K}$ & 0.55 \\
\hline Muniz et al. (2009) & A Neuro-fuzzy System for & & $20 \mathrm{~K}$ & 0.68 \\
\hline Nagi et al. (2008b) & $\begin{array}{l}\text { Fraud Detection in Electricity Distribution } \\
\text { "Non-Technical Loss analysis for detection } \\
\text { of electricity theft using support vector } \\
\text { machines. IEEE 2nd International Power } \\
\text { and Energy Conference (PECon 2008). }\end{array}$ & SVM & Less than $400 \mathrm{~K}$ & 0.53 \\
\hline Nagi et al. (2008a) & $\begin{array}{l}\text { "Detection of abnormalities and electricity } \\
\text { theft using genetic support vector machines. } \\
\text { IEEE Region } 10 \text { Conference TENCON. }\end{array}$ & Genetic SVM & 1172 & 0.63 \\
\hline Nagi et al. (2010b) & $\begin{array}{l}\text { "Improving SVM-based nontechnical loss } \\
\text { detection in power utility using the fuzzy } \\
\text { inference system. IEEE Trans. Power } \\
\text { Delivery, 26: 1284-1285. }\end{array}$ & SVM + Fuzzy & $100 \mathrm{~K}$ & 0.72 \\
\hline Nagi et al. (2010a) & $\begin{array}{l}\text { "Nontechnical loss detection for metered } \\
\text { customers in power utility using support } \\
\text { vector machines. IEEE Trans. Power } \\
\text { Delivery, 25: 1162-1171. }\end{array}$ & SVM Gauss & Less than $400 \mathrm{~K}$ & 0.77 \\
\hline Nizar et al. (2006b) & $\begin{array}{l}\text { "Customer information system data } \\
\text { pre-processing with feature selection } \\
\text { techniques for non-technical losses } \\
\text { prediction in an electricity market. } \\
\text { International Conference on Power System } \\
\text { Technology (PowerCon 2006). }\end{array}$ & Decision tree & $\mathrm{N} / \mathrm{A}$ & 0.99 \\
\hline
\end{tabular}




\begin{tabular}{lllll} 
Table 6: Continue & & & \\
\hline Ramos et al. (2009) & "Fast non-technical losses identification through & OPF & 736 & 0.90 \\
& optimum-path forest. 15th International & SVM gauss & 736 & 0.89 \\
& Conference on Intelligent System Applications & SVM linear & 736 & 0.45 \\
& to Power Systems (ISAP). & NN & 736 & 0.53 \\
Ramos et al. (2012) & "Identification and feature selection of & SVM & $5 \mathrm{~K}$ & 0.96 \\
& non-technical losses for industrial consumers & KNN & $5 \mathrm{~K}$ & 0.96 \\
& using the software WEKA. International & NN & $5 \mathrm{~K}$ & - \\
& Conference on Industry Applications, (CIA' 12). & & \\
Sahoo et al. (2015) & "Electricity theft detection using smart & Regression & 30 & \\
& meter data. IEEE Power and Energy & & & \\
& Society Innovative Smart Grid & & & \\
Spiric et al. (2014) & Technologies Conference (GTC' 15). & & \\
& "Using the rough set theory to detect & Rough sets & N/A & \\
& fraud committed by electricity customers. & & \\
& Int. J. Electrical Power Energy Syst., & & \\
& 62: 727-734. & & \\
\hline & & &
\end{tabular}

Nevertheless, these shortcomings can be minimized and this, if an increased policy accompanies the use of these meters. For example, the following recommendations can help minimize the negative aspects while improving the quality of service.

\section{Advantages}

Theoretical and practical studies have shown that prepayment is currently very successful, owing to the following advantages:

- Cash improvement as customers pay before using electricity

- Limiting collection defects because the customer does not receive electricity if he has not paid in advance

- Reduction in the cost of meter readings

- Reduction in fraud with appropriate facilities

- Anticipation of consumption

- Payment according to financial capacity

- Adjustment of consumption to the financial resources

- Avoidance of unpleasant surprises at the end of the month when faced with an unexpected bill

\section{Disadvantages}

Although prepaid meters have many advantages, the disadvantages cannot be neglected. These shortcomings, which more or less affect the supplier and the customers, are as follows:

- Saturation of the servers of the management units

- Spontaneous failure of the management and sales units

- Difficulties in recovering fixed premiums and royalty

- Difficulties in the supply of energy credits in certain branches, creating long queues

- Consumption of energy greater than that in the case of conventional meters
- Risk of sleeping without electricity for lack of units

- Difficulties related to the levying of the fee

\section{Conclusion}

After presenting the system for the detection of nontechnical losses, a summary of a prepayment system for electric power or other utility commodity distribution using radio frequency identification tag technology to store and transfer value (money or KWh) from the retail vendor to the customer and deliver power to the customer from the power distribution system after the presentation of a fraud detection model for the Cameroon National Electricity Company, using support vector machines was implemented as solution. There are several well-known and generally accepted sources of evidence that prepaid electricity meters stop endless conflicts among customers, ENEO's collection departments, landlords and tenants over unpaid or sometimes rejected bills because they are considered overtaxed, which here constitute commercial or nontechnical losses. In addition, this mode not only enables the supplier to solve collection problems, but also allows the customer to avoid unnecessary wastage of electricity and to better manage it according to their cash flow.

\section{Acknowledgement}

I am thankful to, Ing Joseph Marie DONGUIA, Ing KAMENI Ariel, Ing MBELLE NDZANA and Ing ALADOUM Pascal who helped me in the implementation of this work.

\section{Author's Contributions}

Lekini Nkodo Claude Bernard: Contributed to research design, literature review, model development and manuscript preparation and revision.

Ndzana Benoît, Oumarou Hamandjoda and Fippo Fitime Louis: Contributed to conceptualization, manuscript review, revision and research supervision. 


\section{Ethics}

The authors have no ethical issues that may arise after the publication of this manuscript and confirm that this work is original and has not been published elsewhere.

\section{References}

Amit, J. and B. Mohnish, 2011. A prepaid meter using mobile communication. Int. J. Eng. Sci. Technol., 3: 160-166.

Benessahraoui, E., 1996. Le contrôle des pertes non techniques

d'électricité:http://www.ifdd.francophonie.org/docs/ prisme/Fi-Controle_pertes.pdf

Benjamini, Y. and Y. Hochberg, 1995. Controlling the false discovery rate: A practical and powerful approach to multiple testing. J. Royal Stat. Society Series B, 57: 289-300.

Birch, A.P. and C.S. Ozveren, 1992. An adaptive classification for tariff selection. Proceedings of the 7th International Conference on Metering Apparatus and Tariffs for Electricity Supply, Nov. 17-19, IEEE Xplore Press, Glasgow, UK.

Bjornar, L. and A. Chinatsu, 1999. Fast and effective text mining using linear-time document clustering. Proceedings of the 5th ACM SIGKDD International Conference on Knowledge Discovery and Data Mining, Aug. 15-18, San Diego, pp: 16-22. DOI: $10.1145 / 312129.312186$

Brossette, S.E., A.P. Sprague, J.M. Hardin, K.B. Waites and W.T. Jones, 1998. Association rules and data mining in hospital infection control and public health surveillance. J. Am. Med. Inform. Assoc., 5: 373-381.

Cabral, J.E., J.O.P. Pinto and A.M.A.C. Pinto, 2009. Fraud detection system for high and low voltage electricity consumers based on data mining. Proceedings of the IEEE Power and Energy Society General Meeting, Jul. 26-30, IEEE Xplore Press, Calgary. DOI: 10.1109/PES.2009.5275809

Cabral, J.E., J.O.P. Pinto, E.M. Gontijo and J.R. Filho, 2004. Fraud detection in electrical energy consumers using rough sets. Proceedings of the IEEE International Conference on Systems, Man and Cybernetics, Oct. 10-13, IEEE Xplore Press, The Hague. DOI: 10.1109/ICSMC.2004.1400905

Chang, R.F. and C.N. Lu, 2003. Load profiling and its applications in power market. Proceedings of the IEEE Power Engineering Society General Meeting, Jul. 13-17, IEEE Xplore Press, Toronto. DOI: 10.1109/PES.2003.1270442

Chen, C.S., M.S. Kang, J.C. Hwang and C.W. Huang, 1999. Implementation of the load survey system in taipower. Proceedings of the Transmission and Distribution Conference, Apri. 11-16, IEEE Xplore Press, New Orleans. DOI: 10.1109/TDC.1999.755368
Chicco, G., R. Napoli, F. Piglione, P. Postolache and M. Scutariu et al., 2005. Emergent electricity customer classification. Proc. Generation, Trans. Distribution, 152: 164-172. DOI: 10.1049/ip-gtd:20041243

Christopher, A.V., G. Swaminathan, M. Subramanian and P. Thangaraj, 2014. Distribution line monitoring system for the detection of power theft using power line communication. Proceedings of the IEEE Conference on Energy Conversion, Oct. 13-14, IEEE Xplore Press, Johor Bahru. DOI: $10.1109 /$ CENCON.2014.6967476

Costa, B.C., B.L. Alberto, A.M. Portela, W. Maduro and E.O. Eler, 2013. Fraud detection in electric power distribution networks using an ANN based knowledge-discovery process. Int. J. Artificial Intell. Applic.

Courant, R. and D. Hilbert, 2008. Methods of Mathematical Physics: Partial Differential Equations. 1st Edn., John Wiley and Sons, Weinheim, ISBN-10: 3527617248, pp: 852.

Creedy, J., 2014. Interpreting inequality measures and changes in inequality. Working Paper.

Dangar, D. and S.K. Joshi, 2014a. Electricity theft detection techniques for distribution system in GUVNL. IJREDR.

Dangar, D. and S.K. Joshi, 2014b. Normalization based $\mathrm{K}$ means clustering algorithm. IJREDR.

Depuru, S.S.S.R., L. Wang and V. Devabhaktuni, 2011. Support vector machine based data classification for detection of electricity theft. Proceedings of the IEEE/PES Power Systems Conference and Exposition, Mar. 20-23, IEEE Xplore Press, Phoenix. DOI: 10.1109/PSCE.2011.5772466

Devijver, P.A. and J. Kittler, 1982. Pattern Recognition: A Statistical Approach. 1st Edn., Prentice-Hall, Englewood Cliffs, ISBN-10: 0136542360, pp: 448.

Doorduin, W.A., H.T. Mouton, R. Herman and H.J. Beukes, 2004. « Feasibility study of electricity theft detection using mobile remote check meters. Proceedings of the 7th AFRICON Conference in Africa AFRICON, Sept. 15-17, IEEE Xplore Press, Gaborone, Botswana. DOI: 10.1109/AFRICON.2004.1406697

Duarte, F.J., F. Rodrigues, V. Figueiredo, Z. Vale and M. Cordeiro, 2003. Data mining techniques applied to electric energy consumers characterization.

Espinoza, M., C. Joye, R. Belmans and B. DeMoor, 2005. Short-term load forecasting, profile identification and customer segmentation: A methodology based on periodic time series. IEEE Trans. Power Syst., 20: 1622-1630. DOI: 10.1109/TPWRS.2005.852123

Figueiredo, V., F. Rodrigues, Z. Vale and J.B. Gouveia, 2005. An electric energy consumer characterization framework based on data mining techniques. IEEE Trans. Power Syst., 20: 596-602. DOI: 10.1109/TPWRS.2005.846234 
Filho, J.R., E.M. Gontijo, A.C. Delaiba, E. Mazina and J.E. Cabral et al., 2004. Pinto Fraud identification in electricity company customers using decision tree. Proceedings of the IEEE International Conference on Systems, Man and Cybernetics, Oct. 10-13, IEEE Xplore Press, The Hague, Netherlands. DOI: 10.1109/ICSMC.2004.1400924

Fisher, D., L. Xu, J.R. Carnes, Y. Reich and J. Fenves et al., 1993. Applying AI clustering to engineering tasks. IEEE Expert, 8: 51-60.

DOI: $10.1109 / 64.248353$

Fletcher, R., 2013. Practical Methods of Optimization. 2nd Edn., Wiley, Chichester, ISBN-10: 111872321X, pp: 456.

Fourie, J.W. and J.E. Calmeyer, 2004. A statistical method to minimize electrical energy losses in a local electricity distribution network. Proceedings of the 7th IEEE AFRICON Conference, Sept. 15-17, IEEE Xplore Press, pp: 667-673. DOI: 10.1109/AFRICON.2004.1406768

Friedman, J.H., 1997. Knowledge Discovery and Data Mining. Menlo Park, California: AAAI Press, Data Mining and Statistics.

Gerbec, D., S. Gasperic and F. Gubina, 2003. «Determination and allocation of typical load profiles to the eligible consumers. Proceedings of the IEEE Bologna Power Tech Conference Proceedings, Jun. 23-26, IEEE Xplore Press, Bologna, Italy. DOI: 10.1109/PTC.2003.1304159

Gerbec, D., S. Gasperic, I. Smon and F. Gubina, 2004. Determining the load profiles of consumers based on fuzzy logic and probability neural networks. IEE Proc. Generat. Trans. Distribut., 151: 395-400. DOI: 10.1049/ip-gtd:20040472

Gerbec, D., F. Gubina and Z. Toro, 2005a. Actual load profiles of consumers without real time metering. Proceedings of the Power Engineering Society General Meeting, Jun. 16-16, IEEE Xplore Press, San Francisco. DOI: 10.1109/PES.2005.1489579

Gerbec, D., S. Gasperic, I. Smon and F. Gubina, 2005b. Allocation of the load profiles to consumers using probabilistic neural networks. IEEE Trans. Power Syst., 20: 548-555.

DOI: $10.1109 /$ TPWRS.2005.846236

Ghajar, R.F. and J. Khalife, 2003. Cost/benefit analysis of an AMR system to reduce electricity theft and maximize revenues for electricite du liban. Applied Energy, 76: 25-37. DOI: $10.1016 / \mathrm{S} 0306-2619(03) 00044-8$

Glauner, P., J.A. Meira, P. Valtchev, R. State and F. Bettinger, 2016. The challenge of non-technical loss detection using artificial intelligence: A survey. Int. J. Computat. Intell. Syst., 10: 760-775.

DOI: $10.2991 /$ ijcis.2017.10.1.51
Halkidi, M., Y. Batistakis and M. Vazirgiannis, 2001. On clustering validation techniques. J. Intell. Inform. Syst., 17: 107-145.

Han, J. and M. Kamber, 2012. Data Mining: Concepts and Techniques. 3rd Edn., Elsevier, Morgan Kaufmann Publishing, ISBN-10: 9380931913, pp: 703.

Hodge, V.J. and J. Austin, 2004. A survey of outlier detection methodologies. Artificial Intell. Rev., 22: 85-126.

Hong, L. and L Ning, 2004. Design and implementation of remote intelligent management system for city energy resources base on wireless network. Study Comput. Applic., 12: 237-239.

Karypis, G., H. Eui-Hong and V. Kumar, 1999. Chameleon: Hierarchical clustering using dynamic modeling. Computer, 32: 68-75. DOI: $10.1109 / 2.781637$

Khan, M.F., A. Zoha and R.L. Ali, 2007. Design and implementation of smart billing and automated meter reading system for utility gas. Proceedings of the International Conference on Information and Emerging Technologies, Jul. 6-7, IEEE Xplore Press, Karachi, Pakistan, pp: 1-6. DOI: 10.1109/ICIET.2007.4381338

Koay, B.S., S.S. Cheah, S.Y.H. Chong, P.H.J. Shun and P. Tong et al., 2003. Design and implementation of Bluetooth energy meter. Proceedings of the Joint 4th International Conference on Information, Communication and Signal Processing, Dec. 15-18, IEEE Xplore Press, Singapore, pp: 1474-1477. DOI: 10.1109/ICICS.2003.1292711

Kohavi, R., 1995. A study of cross-validation and bootstrap for accuracy estimation and model selection. Proceedings of the 14th International Joint Conference on Artificial Intelligence, Aug. 20-25, Montreal, Quebec, pp: 1137-1143.

Kou, Y., C.T. Lu, S. Sirwongwattana and Y.P. Huang, 2004. Survey of fraud detection techniques. Proceedigns of the IEEE International Conference on Networking, Sensing and Control, Mar. 21-23, IEEE Xplore Press, Taipei, Taiwan. DOI: 10.1109/ICNSC.2004.1297040

Kwan, B.H. and M. Moghavvemi, 2002. PIC based smart card prepayment system. Proceedings of the Student Conference on Research and Development, Jul. 17-17, IEEE Xplore Press, Shah Alam, Malaysia, pp: 440-443. DOI: $10.1109 /$ SCORED.2002.1033152

Lavrac, N., 1999. Selected techniques for data mining in medicine. Artificial Intell. Med., 16: 3-23. DOI: 10.1016/S0933-3657(98)00062-1

Lekini, N.C.B., B. Ndzana and H. Oumarou, 2017. Evaluation of customer behaviour irregularities in cameroon electricity network using support vector machine. Am. J. Eng. Applied Sci.

DOI: 10.3844/ajeassp.2017 
Ling, Z., S. Chu and B. Guo, 2010. The design of prepayment polyphase smart electricity meter system. Proceedings of the International Conference on Intelligent Computing and Integrated Systems (ISS' 10), pp: 430-432.

Lo, K.L. and Z. Zakaria, 2004. Electricity consumer classification using artificial intelligence. Proceedings of the 39th International Universities Power Engineering Conference, Sept. 6-8, IEEE Xplore Press, Bristol, UK.

Lozano, E. and E. Acufia, 2005. Parallel algorithms for distance-based and density-based outliers. Proceedigns of the 5th IEEE International Conference on Data Mining, Nov. 27-30, Houston. DOI: 10.1109/ICDM.2005.116

Mabrouka, E.G., 2009. Caractérisation aveugle de la courbe de charge électrique: Détection, classification et estimation des usages dans les secteurs résidentiel et tertiaire.

Maheswari, C., R. Jeyanthi, K. Krishnamurthy and M. Sivakumar 2009. Implementation of energy management structure for street lighting system. J. Modern Applied Sci., 5: 6-10.

Malik, S.H.1., K. Aihab and S. Erum, 2009. SMS based wireless Home Appliance Control System (HACS) for automating appliances and security. Sci. Inform. Technol., 6: 887-894.

Markou, M. and S. Singh, 2003. Novelty detection: A review-Part 1: Statistical approaches. Signal Proc., 83: 2481-2497. DOI: 10.1016/j.sigpro.2003.07.018

Mathias, L., 2009. Perte d'énergie dans les réseaux de distribution d'électricité.

Maulik, U. and S. Bandyopadhyay, 2002. Performance evaluation of some clustering algorithms and validity indices. IEEE Trans. Pattern Anal. Mach. Intell., 24: 1650-1654.

DOI: 10.1109/TPAMI.2002.1114856

Muniz et al., 2009. A neuro-fuzzy system for fraud detection in electricity distribution IFSA-EUSFLAT.

Nagi, J., K.S. Yap, S.K. Tiong, S.K. Ahmed and M. Mohamad 2010a. Nontechnical loss detection for metered customers in power utility using support vector machines. IEEE Trans. Power Delivery, 25: 1162-1171. DOI: 10.1109/TPWRD.2009.2030890

Nagi, J., K.S. Yap, S.K. Tiong, S.K. Ahmed and F. Nagi, 2010b. Improving SVM-based nontechnical loss detection in power utility using the fuzzy inference system. IEEE Trans. Power Delivery, 26: 1284-1285. DOI: $10.1109 /$ TPWRD.2010.2055670

Nagi, J., K.S. Yap, F. Nagi, S.K. Tiong and S.P. Koh et al., 2010c. NTL detection of electricity theft and abnormalities for large power consumers in TNB Malaysia. Proceedings of the IEEE Student Conference on Research and Development, Dec. 13-14, IEEE Xplore Press, Putrajaya.

DOI: $10.1109 /$ SCORED.2010.5704002
Nagi, J., K.S. Yap, S.K. Tiong and S.K. Ahmed, 2008a. Detection of abnormalities and electricity theft using genetic support vector machines. Proceedings of the IEEE Region 10th Conference, Nov. 18-21, IEEE Xplore Press, Hyderabad, India, pp: 1-6. DOI: 10.1109/TENCON.2008.4766403

Nagi, J., K.S. Yap, S.K. Tiong, A.M. Mohammad and S.K. Ahmed, 2008b. Non-technical loss analysis for detection of electricity theft using support vector machines. Proceedings of the 2nd IEEE International Power and Energy Conference, Dec. 1-3, IEEE Xplore Press, Johor Bahru, Malaysia, pp: 907-912. DOI: 10.1109/PECON.2008.4762604

Nizar, A.H., J.H. Zhao and Z.Y. Dong, 2006a. Customer information system data pre-processing with feature selection techniques for non-technical losses prediction in an electricity market. Proceedings of the International Conference on Power System Technology, Oct. 22-26, IEEE Xplore Press, Chongqing, China, pp: 1-7. DOI: 10.1109/ICPST.2006.321964

Nizar, A.H., Z.Y. Dong, M. Jalaluddin and M.J. Raffles, 2006b. Load profiling method in detecting nontechnical loss activities in a power utility. Proceedings of the IEEE International Power and Energy Conference, Nov. 28-29, IEEE Xplore Press, Putra Jaya. DOI: 10.1109/PECON.2006.346624

Platt, J.C., 1999. Fast training of support vector machines using sequential minimal optimization. Adv. Kernel Meth.

Ramos, C.C.O., A.N. de Souza, D.S. Gastaldello and J.P. Papa, 2012. Identification and feature selection of non-technical losses for industrial consumers using the software WEKA. Proceedings of the 10th IEEE/IAS International Conference on Industry Applications, Nov. 5-7, IEEE Xplore Press, Fortaleza. DOI: 10.1109/INDUSCON.2012.6451485

Ramos, C.C.O., A.N. de Souza, J.P. Papa and A.X. Falcao, 2009. Fast non-technical losses identification through optimum-path forest. Proceedings of the 15th International Conference on Intelligent System Applications to Power Systems, Nov. 8-12, IEEE Xplore Press, Curitiba. DOI: $10.1109 /$ ISAP.2009.5352910

Ray, S. and R.H. Turi, 2000. Determination of number of clusters in k-means clustering and application in color image segmentation.

Ren, D., B. Wang and W. Perrizo, 2004a. RDF: A density-based outlier detection method using vertical data representation. Proceedings of the 4th IEEE International Conference on Data Mining, Nov. 1-4, IEEE Xplore Press, Brighton, UK. DOI: $10.1109 /$ ICDM.2004.10010 
Ren, D., I. Rahal and W. Perrizo, 2004b. A vertical outlier detection algorithm with clusters as byproduct. Proceedings of the 16th IEEE International Conference on Tools with Artificial Intelligence, Nov. 15-17, IEEE Xplore Press, Boca Raton. DOI: 10.1109/ICTAI.2004.22

Rengarajan, S. and S. Loganathan, 2012. Power theft prevention and power quality improvement using fuzzy logic. Int. J. Electrical Electron. Eng.

Sahoo, S., D. Nikovski, T. Muso and K. Tsuru, 2015. Electricity theft detection using smart meter data. Proceedings of the IEEE Power and Energy Society Innovative Smart Grid Technologies Conference, Feb.18-20, IEEE Xplore Press, Washington. DOI: $10.1109 /$ ISGT.2015.7131776

Scaradozzi, D. and G. Conte, 2003. Viewing home automat ion systems as multiple agents systems. RoboCUP2003, Padova, Italy.

Scholkopf, B., 1997. Support vector learning. CiteSeer.

Sharma, S. and S. Shoeb, 2011. Design and Implementation of wireless automatic meter reading system. Int. J. Eng. Sci. Technol., 3: 2329-2334.

Sheriff, G. and K. Maguire, 2013. Ranking distribution of environmental outcomes across population groups. Nat. Center Environ. Econom.

Shwehdi, M.H. and C. Jackson, 1996. A microprocessor based digital wattmeter system design. Proceedings of the 31st Intersociety Conference on Energy Conversion Engineering, (ECE' 96), pp: 1840-1845.

Smith, T.B., 2004. Electricity theft: A comparative analysis. Energy Policy, 32: 2067-2076. DOI: $10.1016 / \mathrm{S} 0301-4215(03) 00182-4$

Spiric, J.V., S.S. Stankovic, M.B. Docic and T.D. Popovic, 2014. Using the rough set theory to detect fraud committed by electricity customers. Int. J. Electrical Power Energy Syst., 62: 727-734. DOI: $10.1016 /$ j.ijepes.2014.05.004
Stanescu, D., B. Ciubotaru-Petrescu, D. Chiciudean and R. Cioarga, 2006. Wireless solutions for telemetry in civil equipment and infrastructure monitoring. Proceedings of the 3rd Romanian-Hungarian Joint Symposium on Applied Computational Intelligence (ACI' 06).

Steinbach, M., G. Karypis and V. Kumar, 2000. A comparison of document clustering techniques.

Vapnik, V. and A. Chervonenkis, 1974. Theory of pattern recognition.

Vapnik, V.N., 1997. The nature of statistical learning theory. IEEE Trans. Neural Netw., 8: 1564-1564. DOI: $10.1109 /$ TNN.1997.641482

Verdu, S.V., M.O. Garcia, F.J.G. Franco, N. Encinas and A.G. Marin et al., 2004. Characterization and identification of electrical customers through the use of self-organizing maps and daily load parameters. Proceedings of the IEEE PES Power Systems Conference and Exposition, Oct. 10-13, IEEE Xplore Press, New York. DOI: 10.1109/PSCE.2004.1397641

Yao, R. and K. Steemers, 2005. A method of formulating energy load profile for domestic buildings in the UK. Int. J. Energy Buil., 37: 663-671.

Zakaria, Z. and K.L. Lo, 2002. Load profiling in the new electricity market. Proceedings of the Student Conference on Research and Development, Jul. 17-17, IEEE Xplore Press, Shah Alam.

DOI: 10.1109/SCORED.2002.1033111

Zhang, J., W. Oghanna and C.L. Bai, 1998. A DSP based electricity meter with remote reading. Proceedings of the 4th International Conference on Signal Processing, Oct. 12-16, IEEE Xplore Press, Beijing, China, pp: 1581-1584. DOI: 10.1109/ICOSP.1998.770928

Zhou, Y. and X.D. Chen, 2015. A dynamic programming algorithm for leveraging probabilistic detection of energy theft in smart home. IEEE Trans. Emerg. Top. Comput., 3: 502-513.

DOI: $10.1109 /$ TETC.2015.2484841 